\title{
"Can We Declare Victory and Move On?" The Case Against Funding Burden-of-Disease Studies
}

\author{
Steven Kymes
}

Published online: 13 August 2014

(C) Springer International Publishing Switzerland 2014

\begin{abstract}
Resources devoted to the development of burden-of-disease studies detract from much needed costeffectiveness and cost-benefit studies. Practitioners need to help funders of burden-of-disease projects recognize the potential of all tools of decision analysis and economic evaluation in improving the efficiency and equity for the health care system.
\end{abstract}

\section{Key Points for Decision Makers}

Burden-of-disease studies do not provide policy makers the information needed to make important resource allocation decisions.

Despite this fact, funders in the USA fund burden-ofdisease studies on a disproportionate basis.

Practitioners of economic evaluation have a responsibility to help funders understand the limitations of burden-of-disease studies and encourage them to fund projects that provide the information necessary to support better decision making.

In the fall of 2006, I had the privilege of being on the "Editors' Choice" panel for the American Academy of

\author{
S. Kymes $(\square)$ \\ The Medwin Group, St. Louis, MO, USA \\ e-mail: smkymes@gmail.com
}

S. Kymes

Washington University School of Medicine, St. Louis, MO, USA
Ophthalmology (AAO) as the discussant for an excellent paper synthesizing the results of the National Health and Nutrition Examination Survey (NHANES) and Medical Expenditure Panel Survey (MEPS) studies to estimate the annual financial burden of correcting refractive error (i.e., myopia and presbyopia) in the USA [1]. The authors were distinguished researchers at the National Eye Institute (NEI) with a long history of high-quality research. The study being presented was no exception. This policy study was not typical of those conducted by the NEI epidemiologists, but the methods were sound and the writing clear and concise. I stipulated to this in my opening remarks, and pointed out that during that same year two similarly distinguished teams of university-based researchers published well written, broadly based, rigorous studies of the burden of visual impairment [2, 3]. I concluded my opening remarks by saying, "These are not the first studies of the economic burden of visual impairment. In the past decade there were several similarly well done studies. It is clear that we have established that visual impairment is bad. Can we declare victory and move on?"

Burden-of-disease studies such as the one I discussed for the AAO are among the most commonly seen forms of economic evaluation. A PubMed search in February 2014 using the term "economic burden" yielded 8,386 studies. In contrast, the terms "cost-benefit", "cost-effectiveness" and "cost-utility" when paired with "economic evaluation" (to restrict the inclusion of non-policy studies), yielded 2,949, 3,471, and 478 studies respectively. Of the 8,386 studies of economic burden located using this search strategy, $46 \%(3,683)$ had publication dates in the last 5 years.

I do not claim that this perfunctory review of the health economic literature is either exhaustive or representative, but it should serve as a warning to thoughtful practitioners 
of economic evaluation of health programs. The purpose of our science is to inform policy makers allocating scarce resources of the relative cost and benefit of programs that relieve the economic burden of disease [4], and it is our responsibility as those who understand it best to be the strongest advocates for our methods and science with the decision makers we hope to inform. Burden-of-disease studies do not provide information concerning the benefit of the intervention to treat or prevent disease. Indeed, by definition, a burden-of-disease study only characterizes the magnitude of the impact of disease on the life of an individual and society. The results provide scant information to the policy maker seeking to insure efficient allocation of resources. In contrast, cost-benefit, cost-effectiveness and cost-utility studies answer this question explicitly by putting relief of the disease burden in context with the resources needed to fund the program.

It is reasonable to ask why a study design which provides policy makers with so little useful information is so frequently conducted in an era where there is universal concern with rising health care costs. Arguably, the popularity of any study is driven largely by the priorities of research funders attempting to influence policy makers. Thus we might gain some insight into the preference of study type by considering the policy environment faced by funders. For instance, in Europe and Canada, formal economic evaluation is required of manufacturers seeking payment for new technologies; thus, we would expect to see considerable support from manufacturers for costeffectiveness and cost-utility studies in these jurisdictions. In contrast, in the decentralized policy environment of the USA, few payors require a formal economic evaluation to support coverage [5] and guidelines of the Academy of Managed Care Pharmacy are agnostic concerning the role of burden-of-illness studies versus cost-effectiveness studies [6]. Indeed, in the superheated health policy environment in the USA, there is open hostility and outright prohibition of the use of economic evaluation by government payors [7, 8]. At the same time, there is intense competition between patient advocacy groups, medical associations, research institutions and governmental agencies to obtain funding to support disease-specific research programs. Thus, we would expect to see considerable support for studies providing evidence of the relative burden of disease to support advocacy with policy makers who control research funds. Our results provide some evidence that this might be the case. In our PubMed study, we found that $25 \%$ of burden-of-disease studies were from the USA, while only $10 \%$ of the cost-benefit/cost-effectiveness/costutility studies identified were from US teams.

This is not to say that cost-of-illness studies are irrelevant. Indeed, they can play an important role by providing important inputs to the models employed for cost- effectiveness and cost-utility studies [6]. However, we should insure that funders and policy makers do not view such studies as an end in themselves. Thus, we as practitioners in the USA should be concerned that a disproportionate share of research support for economic evaluation is going to support such studies. It must be recognized that as with any activity there is an opportunity cost associated with a research agenda favoring burden-of-disease studies. Scholars who conduct cost-effectiveness and cost-benefit studies are a limited social resource, and practitioners who conduct burden-of-illness studies are not conducting costeffectiveness and cost-utility studies. This is problematic within the USA, where, despite a recent slowing of the rate of increase of the cost of health care, health spending per capita remains twice that of the average developed nation [9]. We should be concerned that US government agencies who would be expected to support initiatives to improve efficiency of health care spending maintain an anemic portfolio of projects directed towards improving allocation of health resources. The Agency for Healthcare Research and Quality (AHRQ) maintains a list of 700 comparative effectiveness projects funded since 2010 totaling over US\$1 billion in funding. Of these, 72 , or $10.3 \%$, include the term "cost-effectiveness" in the abstract provided, only one has the term "economic evaluation" in the project abstract, and none include the terms "cost-utility" or "cost-benefit" (see http://gold.ahrq.gov/projectsearch/grant_ search_result.jsp?CSV=1\&DESCR=1\&SORT=AWD\&DESC= $1 \&$ PORT $=\mathrm{A}$ accessed February 13, 2014). The Value portfolio of AHRQ provides essential resources for the conduct of economic evaluation, such as the Medical Expenditure Panel Survey and the Healthcare Cost and Utilization Project. The Agency also acts as a clearinghouse for guidelines and quality indicators. However, there is no evidence that there is an intramural or extramural economic evaluation agenda (see http://www.ahrq.gov/cpi/ portfolios/value accessed February 13, 2014).

Funders cannot be faulted for supporting research that supports their agenda, and in particular, the AHRQ cannot be faulted for maintaining a research agenda that recognizes the political context in which it exists. The agency has faced extinction on numerous occasions when its leaders pursued a politically unpopular research agenda $[10,11]$, and the current agenda reflects the task faced by an agency attempting to conduct important research in a volatile policy environment. However, as practitioners we do not face the same limitations and we have an essential role in making certain that the consequence of these funding decisions is understood. We must insure that our funders understand the social benefit created through full use of the highly specialized economic evaluation toolbox. We serve no valuable scientific or social purpose when we lack the courage to engage funders and policy makers in 
this discussion. We must help them move beyond the parochial goals of advocacy-focused burden-of-disease studies and grasp the social benefit of cost-effectiveness and cost-benefit studies.

It is our responsibility as members of the economic evaluation community to help funders understand that rather than expending scarce resources on yet another project to estimate the societal burden of blindness (or heart disease, lung cancer, stroke, etc.), there is greater benefit created by a value-of-information study that targets future research funding to specific areas of critical understanding of the diseases. It is the responsibility of those of us who sit on review panels to help project officers and agency leaders to understand that a sophisticated sensitivity analysis supporting risk stratification guidelines will create greater wellness among patients with disease than assessing the impact of chronic disease on work productivity for the fourth time this decade. Most importantly, we must remove the ridiculous and undeserved political stigma from costeffectiveness studies by having the courage to leverage our relationships with policy makers and funders to help likeminded staffers at AHRQ, Center for Disease Control (CDC), and the National Institutes of Health (NIH) demonstrate that economic evaluation is a tool that can address inequity and inefficiency in the US health care system when applied in a rigorous and systematic fashion.

Engaging in this conversation takes courage. We might need to tell our funders "No" when they are asking for yet another study that will not advance efficiency in the health system, and thus we put our funding streams at risk. But if we are going to ask policy makers to show political courage, we must be willing to do the same.

Given my poor manners it is not surprising that I have never been invited back to reprise my discussant role at AAO's Editor's Choice Symposium. However, I hope the readers of Pharmacoeconomics might better appreciate the root of my frustration than an audience of eye doctors. It is understandable that clinicians, politicians and patient advocacy organizations seek to fund studies that they believe advance their interests. That is all the more reason it is incumbent upon us as scientists to see that funders understand the social burden associated with their decisions. We long ago achieved victory in helping decision makers to understand the burden of disease. Now we must move on by applying the entire tool box of economic evaluation and in doing so truly mitigate disease burden while preserving prosperity and equity in our society.

Disclosure and Disclaimer Dr. Kymes is the principal and sole owner of The Medwin Group, a consultancy which conducts economic evaluation studies for pharmaceutical manufacturers, device companies and governmental agencies. His scope of work includes both cost-of-illness and cost-effectiveness studies. The opinions expressed in this column are exclusively that of the author and do not represent the position of clients of The Medwin Group.

\section{References}

1. Vitale S, Cotch MF, Sperduto R, Ellwein L. Costs of refractive correction of distance vision impairment in the United States, 1999-2002. Ophthalmology. 2006;113(12):2163-70.

2. Rein DB, Zhang P, Wirth KE, et al. The economic burden of major adult visual disorders in the United States. Arch. Ophthalmol. 2006;124(12):1754-60.

3. Frick KD, Gower EW, Kempen JH, Wolff JL. Economic impact of visual impairment and blindness in the United States. Arch. Ophthalmol. 2007;125(4):544-50.

4. Gold MR, Siegel JE, Russell LB, Weinstein MC. Cost-effectiveness in health and medicine. 1st ed. New York: Oxford University Press; 1996.

5. Neumann PJ, Sullivan SD. Economic evaluation in the US: what is the missing link? Pharmacoeconomics. 2006;24(11):1163-8.

6. AMCP Format Executive Committee. The AMCP Format for Formulary Submissions (Version 3.1). Academy of Managed Care Pharmacy; December 2012.

7. Patient Protection and Affordable Care Act. 42 USC $\$ 18001$. vol 111th Congress. 2009-2010.

8. Gusmano MK. Policy forum: overcoming inequalities: the affordable care act and cancer treatment virtual mentor. Am. Med. Assoc. J. Ethics. 2013;15(8):692-6.

9. Organization for Economic Cooperation and Development. OECD Health Data 2013. 2013; http://www.compareyour country.org/health/health-spending-gdp?cr=oecd\&lg=en.

10. Gray BH, Gusmano MK, Collins SR. AHCPR and the changing politics of health services research. Health Aff. (Millwood). JanJun 2003;Suppl Web Exclusives:W3-283-307.

11. Lin K. How politically unpopular research from AHRQ helps us make better medical decisions. 2012. http://www.thedoctor weighsin.com/how-politically-unpopular-research-from-ahrq-helpsus-make-better-medical-decisions/. Accessed 12 July 2012. 